\title{
PROCESSANDO O CUIDADO “DO NÓS” NAS RELAÇÕES/INTERAÇÕES ESTABELECIDAS POR PROFISSIONAIS DE ENFERMAGEM E DE SAÚDE
}

Maria Aparecida Baggio', Alacoque Lorenzini Erdmann²

${ }^{1}$ Enfermeira. Doutora em Enfermagem. Docente do Departamento de Enfermagem da Universidade Estadual do Oeste do Paraná. Cascavel, PR, Brasil.

${ }^{2}$ Enfermeira. Doutora em Filosofia da Enfermagem. Docente do Departamento de Enfermagem da Universidade Federal de Santa Catarina. Florianópolis, SC, Brasil.

RESUMO: Este estudo objetivou compreender o cuidado "do nós" processado nas relações e interações humanas estabelecidas por profissionais de enfermagem e de saúde em um hospital universitário ao sul do Brasil. Apresentam-se uma categoria e quatro subcategorias que representam as estratégias, componente do modelo paradigmático, segundo a Teoria Fundamentada nos Dados, método do estudo. A coleta de dados foi realizada com quatro grupos amostrais, totalizando 25 participantes, no período de março a julho de 2011, por meio de entrevista semiestruturada. Tais subcategorias constituem os resultados: Sendo o cuidado "do nós" relacional e processual; Processando o cuidado "do nós" no ambiente de trabalho; Relacionando o cuidado "do nós" ao cuidado coletivo; Significando a relação e interação de cuidado junto aos pacientes e familiares. As relações e interações estabelecidas entre os profissionais e esses junto aos pacientes e familiares processam o cuidado "do nós" de forma ampla e complexa.

DESCRITORES: Enfermagem; Relações interpessoais; Ambiente de trabalho.

\section{CARE OF "THE WE" AS PROCESSED IN THE RELATIONSHIPS/INTERACTIONS ESTABLISHED BY NURSING AND HEALTH PROFESSIONALS}

\begin{abstract}
This study aimed to understand how care of "the we $^{\prime \prime}$ is processed in the human relationships and interactions established by nursing and health professionals in a university hospital in the South of Brazil. The results revealed one category and four subcategories that represented the strategies adopted by these professionals, a component of the paradigmatic model, according to grounded theory. Data were collected in four sample groups by conducting semi-structured interviews with a total of 25 participants between March and July 2011. Specifically, the subcategories were: care of "the we" is relational and procedural; how care of "the we" is processed in the working environment; how care of "the we" is associated with collective care; and signifying relationships and interactions involved in the process of caring for patients and families. Care of "the we" is processed broadly and complexly in the relationships and interactions established among professionals and between professionals and patients and family members.
\end{abstract}

DESCRIPTORS: Nursing; Interpersonal relations; Working environment.

\section{PROCESANDO EL CUIDADO “DEL NOSOTROS" EN LAS RELACIONES/INTERACCIONES ESTABLECIDAS POR PROFESIONALES DE ENFERMERÍA Y DE SALUD}

RESUMEN: Este estudio tuvo la finalidad de comprender el cuidado "del nosotros" procesado en las relaciones e interacciones humanas establecidas por profesionales de enfermería y de salud en un hospital universitario del sur de Brasil. Fueron presentadas una categoría y cuatro subcategorías que representan las estrategias, componiendo el modelo paradigmático, de acuerdo a la Teoría Fundamentada en los Datos, método del estudio. Los datos fueron obtenidos con cuatro grupos amostrales, totalizando 25 participantes, en el periodo de marzo a julio de 2011, por medio de entrevista semiestructurada. Tales subcategorías constituyen los resultados: Siendo el cuidado "del nosotros" relacional y procesual; Procesando el cuidado "del nosotros" en el ambiente de trabajo; Relacionando el cuidado "del nosotros" al cuidado colectivo; Significando la relación e interacción de cuidado con los pacientes y familiares. Las relaciones e interacciones establecidas entre los profesionales y de eses con los pacientes y familiares procesan el cuidado "del nosotros" de modo amplio y complejo.

DESCRIPTORES: Enfermería; Relaciones interpersonales; Ambiente de trabajo.

*Artigo extraído da tese intitulada: "Acontecendo o cuidado "do nós" nos movimentos e ondulações dos processos interativos no ambiente hospitalar". Universidade Federal de Santa Catarina, 2012.

Autor Correspondente:

Maria Aparecida Baggio

Universidade Estadual do Oeste do Paraná

Rua Osvaldo Cruz, 2602, ap 1303 - 85810-150 - Cascavel, PR, Brasil

E-mail: mariabaggio@yahoo.com.br
Recebido: 05/05/2015

Finalizado: 24/06/2015 


\section{INTRODUÇÃO}

O cuidado, na sua compreensão ampla e complexa, é entendido como uma forma de estar-com, de perceber, relacionar-se e preocupar-se com outro ser humano em dado tempo e espaço, cuja relação acontece face a face. As responsabilidades, habilidades, relações interpessoais, os sentimentos, saberes e (re)conhecimentos instituídos entre os seres ${ }^{(1-2)}$ constituem e permeiam o cuidado.

Os profissionais de enfermagem e de saúde como seres interdependentes, inter-relacionamse e relacionam-se com outras pessoas em dimensões diversas, visto que dependem de relações sociais, da interação com os amigos, família, colegas de trabalho e com pessoas que não conhecem. Esta interdependência é condição inerente à atuação profissional no campo da saúde humana.

No processo de cuidar, os profissionais estabelecem relações de proximidade com outros sujeitos, culminando em processos interativos mútuos que favorecem o encontro entre as pessoas e o estabelecimento de vínculos afetivos. Entretanto, para compreender as interações estabelecidas, é necessário o reconhecimento das particularidades inerentes à subjetividade dos sujeitos envolvidos, das multiplicidades de interpretações possíveis pela mente humana e dos sentimentos que permeiam as relações e interações de cuidado. Tais reconhecimentos demandam ampliar o olhar e estar aberto para a compreensão dos fatos e fenômenos múltiplos que ocorrem em um mesmo ambiente e permeiam as ações de cuidado(3).

Por essa razão, é preciso considerar, nas relações e interações humanas, a complexidade subjacente. Para isso, demanda-se entender que, à luz do pensamento complexo ${ }^{(4-5)}$, os profissionais de enfermagem e de saúde são seres complexos, uni e multidimensionais, singulares e plurais; são biológicos, afetivos, psíquicos, sociais e racionais, que agregam singularidades e pluralidades de outros seres, advindas das relações e interações estabelecidas. Como sistemas vivos, os profissionais são considerados sistemas abertos. Por isso, são seres de trocas, interação, interrelação e que dependem das relações externas que estabelecem com o meio para o próprio desenvolvimento(4).

O cuidado "do nós", tema em construção pela enfermagem, é representado pelas relações e interações que se estabelecem entre os profissionais de enfermagem e de saúde para uma convivência saudável. Esses, ao se relacionarem e interagirem vivenciam momentos de trocas de experiências; fundam interdependências e estabelecem o cuidado necessário para seu crescimento e realização pessoal. Assim, o objetivo deste artigo é compreender o cuidado "do nós" processado nas relações e interações humanas estabelecidas por profissionais de enfermagem e de saúde em um hospital universitário.

\section{METODOLOGIA}

A pesquisa foi desenvolvida no período de março a julho de 2011, em um hospital universitário localizado ao sul do Brasil. O referencial metodológico do estudo foi a Teoria Fundamentada nos Dados, a qual busca explorar o significado dos fenômenos investigados e permite realizar inter-relação entre os dados bem como a análise comparativa constante ${ }^{(6)}$.

A coleta de dados, conforme a Teoria Fundamentada nos Dados ${ }^{(6)}$, foi guiada por amostragem teórica, constituída por quatro grupos amostrais, os quais foram compostos por profissionais de enfermagem e de saúde, totalizando 25 participantes. Foram critérios de inclusão para participação na pesquisa, ser profissional de enfermagem e de saúde, atuante na instituição do estudo, com disponibilidade para contribuir com a pesquisa.

O primeiro grupo amostral foi formado por seis profissionais de enfermagem de uma unidade de cuidados cirúrgicos, os quais apontaram a formação do segundo grupo, composto por cinco profissionais de saúde (psicóloga, médico, enfermeira, farmacêutica, nutricionista) dessa unidade. Visando à comparação de dados e à confirmação de hipóteses, o terceiro grupo foi formado por 11 profissionais de enfermagem e de saúde (enfermeiros, técnicos de enfermagem, médicos, psicóloga, fonoaudióloga, assistente social) de uma unidade de cuidados intensivos. Os fenômenos foram comparados e hipóteses confirmadas, obtendo-se a saturação dos dados com a formação do quarto grupo, constituído por médico, enfermeiro e farmacêutico, sendo esses, respectivamente, diretor geral, de enfermagem e de apoio assistencial do hospital.

A coleta de dados ocorreu por meio de entrevista semiestruturada, registrada através de gravação digital de voz, cujo diálogo com o entrevistado foi iniciado com a seguinte questão: Fale-me sobre o significado do cuidado "do nós", a partir da sua experiência. As demais 
questões foram direcionadas pelas respostas dos participantes. Para manter o anonimato das informações, os participantes foram identificados pela letra $\mathrm{P}$ (Participante), seguida de número ordinal correspondente às falas (P1, P2... P25.). A participação dos sujeitos foi voluntária, autorizada mediante assinatura do Termo de Consentimento Livre e Esclarecido. O pensamento complexo foi o referencial teórico do estudo ${ }^{(4-5)}$.

Durante o processo de coleta e análise, guiado por amostragem teórica, os dados coletados foram transcritos, codificados e, ao serem analisados, conduziram para a próxima coleta e análise comparativa de dados, sucessivamente, até a saturação dos dados. Os códigos foram agrupados e as categorias e subcategorias definidas e desenvolvidas em termos de suas propriedades e dimensões, seguindo-se o processo de codificação aberta, axial e seletiva ${ }^{(6)}$.

O processo analítico foi construído na perspectiva paradigmática, constituída por cinco componentes (contexto, causa, condição interveniente, estratégias e consequências) que explicam o fenômeno. Os dados a serem apresentados e discutidos referem-se às estratégias que os profissionais de enfermagem e de saúde se utilizam e processam nas relações e interações para atingir o cuidado "do nós". Essas estratégias são representadas por uma categoria que comporta quatro subcategorias advindas das conexões teóricas realizadas, resultantes de um processo analítico explicativo das experiências e relações de cuidado "do nós", significadas pelos profissionais.

O projeto de pesquisa foi aprovado pelo Comitê de Ética em Pesquisa com Seres Humanos da Universidade Federal de Santa Catarina, sob o $n^{\circ} 860 / 2010$. Os critérios éticos de pesquisas envolvendo seres humanos foram respeitados em todas as etapas da pesquisa.

\section{RESULTADOS}

Processando o cuidado "do nós" nas relações/ interações estabelecidas por profissionais de enfermagem e de saúde

Esta categoria sustenta que o cuidado "do nós" processado nas relações e interações humanas estabelecidas por profissionais de enfermagem e de saúde, no ambiente hospitalar, é compreendida por quatro subcategorias, descritas a seguir:

\section{Sendo o cuidado "do nós" relacional e processual}

O cuidado "do nós" envolve processos relacionais entre indivíduos, em determinado contexto, cujas relações são maximizadas por afinidade, convivência e proximidade física e temporal estabelecida que, consequentemente, conduzem a uma relação de intimidade, troca, diálogo e de ajuda mútua, bem como à constituição de vínculos afetivos.

O cuidado está dentro das nossas afinidades. (P20)

Olhar para a pessoa e saber se ela está bem. Essa percepção se dá na convivência. (P22)

Cada turno tem preocupação com os seus membros. O turno da manhã com o da tarde tem muitas trocas, eles têm uma relação bem próxima. (P4)

A relação de cuidado "do nós" está ligada ao modo de ser e de se relacionar, característicos de cada pessoa. É relativa à consciência do cuidar recíproco na interação constituída entre os seres, desde os profissionais de nível técnico até os gestores. Neste sentido, as relações de cuidado se processam com os vários 'nós', nos diferentes grupos de iguais, ou seja, entre os profissionais que atuam no mesmo turno, na mesma unidade ou função com fins comuns.

[...] como um dever de cidadão de ajudar o outro, não como profissão. (P1)

[...] um profissional cuidar do outro no dia-a-dia, tratar bem, respeitar. É um cuidado recíproco, alguns mais, outros menos, uns de um jeito mais e outros menos expansivo. (P7)

[...] relação com os nós de iguais que trabalham em uma mesma unidade, mesma instituição, que tem uma meta, que tem um fim em comum. (P17)

As relações de cuidado "do nós", também entendidas como redes de cuidado, estão em constante crescimento, movimento e mutação a partir de entradas, saídas e trocas entre os sujeitos no processo relacional. Como esse processo ocorre por interação humana, a rede de relações é constituída de expectativas de uns em relação aos outros, de fragilidades e de falhas inerentes aos próprios seres. Assim, a postura ativa, madura e flexível é necessária para que os pontos da rede se mantenham conectados e processem o cuidado "do nós".

Uma rede que está em constante crescimento, sendo tecida por sujeitos diferentes. Conectar e manter esses pontos conectados não é fácil, se um ponto se solta a rede fica frágil. (P17)

Você sempre tem uma expectativa em relação ao outro e nem todas as expectativas da gente são 
realizadas [...] tem que ser flexível uns em relação aos outros. (P21)

No processo relacional, os seres estão interligados por meio de emoções sentidas e manifestadas. A mútua troca acontece numa reação em cadeia, seja de emoções e sensações positivas, ou não; seja junto ao grupo de iguais no trabalho, seja junto à família.

Acho que tudo é interligado, um com outro. (P16)

Se eu cuidar da equipe, a equipe vai cuidar da família dela e isso vai voltar pra mim. (P19)

\section{Processando o cuidado "do nós" no ambiente de trabalho}

Os profissionais de saúde, em especial os da enfermagem, convivem quase que diariamente por um período de seis a doze horas no ambiente de trabalho. Nesse conviver, o cuidado "do nós" processa-se por meio de ações e atitudes de cuidado entre os profissionais. Inicia-se ao chegar ao ambiente de convívio e de interação, o qual importa expressar o desejo de um bom dia, uma boa tarde, cumprimentando a todos com entusiasmo. Logo, o cuidado "do nós" é processado desde o modo de chegar e de abordar as pessoas, com demonstração de respeito, de interesse e de preocupação com o outro.

É se preocupar com o outro desde que você chega à unidade, dizer: Bom dia! Boa tarde! [...] o jeito de se chegar, o jeito de se importar, são detalhes tão pequenos. (P20)

As ações e atitudes de cuidado, identificadas como responsáveis pelo processar o cuidado "do nós" no convívio intergrupal, ocorrem pela presença, escuta, atenção, pelo sorriso, elogio, empatia, acolhimento, respeito, valorização, disponibilidade, preocupação, carinho, zelo, afeto e solidariedade que um profissional manifesta em relação ao outro no espaço de trabalho e de cuidado. A descontração é permitida, quando oportuna, pois a brincadeira e o riso permitem processar o cuidado entre os sujeitos e do ambiente de relações.

Escutar, elogiar, brincar, rir, sorrir. (P20)

É mais esta parte de relacionamento, preocupação, atenção, de ouvir, acolher, ter empatia, disponibilidade. (P5)

Quando você consegue respeitar, valorizar, cuidar, nas pequenas coisas. (P7)

Solidariedade é algo extremamente importante para a gente ter relações de cuidado. (P22)

O cuidado "do nós" também se processa na pausa para o lanche, quando os profissionais se encontram para tomar um café, para conversar e confraternizar. Isso permite uma relação mais próxima, um momento de diminuir a tensão advinda dos compromissos e responsabilidades profissionais/do trabalho.

No horário que a gente vai tomar o café, a gente tenta se integrar para ter uma relação mais próxima. (P5)

\section{Relacionando o cuidado "do nós" ao cuidado coletivo}

Como ser social, o profissional interage, associa-se e integra-se a outras pessoas, as quais passam a ser objeto de atenção e preocupação ao pensar na perspectiva do coletivo/"do nós". Pensar o cuidado "do nós" significa pensar no coletivo; significa deixar de pensar no singular e passar a pensar no plural, no cuidado de múltiplas pessoas e/ou grupos de pessoas; significa pensar uns nos outros, no bem-estar e no cuidado dos envolvidos de um mesmo grupo social, que possuem características distintas e específicas.

[...] as pessoas pensarem umas nas outras no ambiente de trabalho. Acho que a gente não pode só pensar na gente, só no nosso bem estar, porque a gente cuida de um outro ser humano, convive com outro ser humano, então temos que pensar no bemestar coletivo. (P5)

O cuidado "do nós" integra e envolve uma multiplicidade de sujeitos que se interrelacionam no âmbito hospitalar e fora dele. $\mathrm{Na}$ perspectiva do cuidado coletivo, vai além das relações profissionais, das relações com o paciente e sua família, envolve também outras relações de cuidado socialmente estabelecidas, perspectivando o cuidado coletivo numa interação múltipla, sensível e criativa.

Esse nós coletivo [...] vai além do profissional, do paciente e da família do paciente; [...] envolve também as relações do profissional fora do seu ambiente de trabalho. (P18)

Nos movimentos do cuidado, as relações interpessoais com os diversos "nós" se tecem na subjetividade e singularidade dos seres, a partir de como cada sujeito percebe o outro. $\mathrm{O}$ atendimento das necessidades particulares desse(s) outro(s) constituem o cuidado "do nós", ainda, quando se considera a heterogeneidade infinita do indivíduo que vive e depende 
da sociedade, do grupo, do coletivo, para o estabelecimento das relações de cuidado.

O cuidado "do nós" faz parte das relações interpessoais por sermos subjetivos e diferentes uns dos outros, parte de um trabalho coletivo, de um trabalho relacional. (P17)

As relações coletivas implicam uma pluralidade de acontecimentos, ações, interações, retroações pertencentes ao que é coletivo e plural. Nessas relações, os profissionais, em suas singularidades, possuem traços da multiplicidade de relações estabelecidas, ou seja, características de outros indivíduos adquiridas na convivência.

\section{Significando a relação e interação de cuidado junto aos pacientes e familiares}

Os profissionais de enfermagem e de saúde incitam o pensar complexo na perspectiva do cuidado "do nós". Remetem-no a um cuidado coletivo, cuja atenção primeira é o paciente, que traz consigo seus familiares e pessoas próximas. A relação de cuidado junto aos pacientes e seus familiares constituem importante significado aos profissionais. É permeada de cuidado, de carinho, de preocupação, de acolhimento, de sensibilidade, de respeito, reciprocidade, empatia, toque.

O foco são os pacientes. É impossível pensar no paciente sem pensar nos acompanhantes, nos familiares. Eles precisam ser acolhidos de cuidado, respeito, reciprocidade, empatia. (P7)

A atenção e preocupação dos profissionais com os pacientes e familiares vai além da interação espacialmente constituída no nível hospitalar. O planejamento da alta do paciente é pensado para o momento em que a família assumirá os cuidados, sendo referenciados outros níveis de saúde para continuidade da assistência ao paciente.

Faço muita contrarreferência [...] o link entre os níveis de complexidade. (P11)

Esse cuidado que se tem com o paciente além do hospital; como vai ser em casa [...]. (P18)

A interação de cuidado entre os profissionais, pacientes e familiares é permeada de ações e atitudes altruístas, delineada por um mútuo benquerer, com características de bondade, generosidade, solidariedade e espiritualidade, próprias de pessoas que se inclinam ao cuidado de outros como um bem a si mesmo. Isso representa a importância e a nobreza das atitudes e ações humanas nas relações de cuidado "do nós".
As famílias trazem bolo para a equipe [...] um agradecimento, um cuidado, uma forma de dizer: obrigado pelo que você está fazendo [...] vocês também precisam ser cuidados. (P7)

Quando tem pacientes graves aqui, eu sempre coloco o nome lá no grupo de oração [...] faço oração para o paciente aqui dentro, mesmo baixinho. (P3)

\section{DISCUSSÃO}

De acordo com os achados do estudo, uma relação promotora de cuidado revela-se em ações e atitudes exclusivamente humanas, imbuídas de atenção, respeito, empatia e zelo entre os sujeitos envolvidos $^{(7)}$. Essas ocorrem quando uma pessoa percebe a outra como partícipe importante da sua vida, visto que são atos conscientes, intencionais e/ou controláveis; que têm poder de ação transformadora na relação entre os sujeitos ${ }^{(8)}$. No entanto, antes mesmo de ser e realizar-se em uma ação ou atitude, o cuidado expressa um modo de ser, de estar, de sentir e (con)viver intrinsecamente, relacionado à essência do ser do homem ${ }^{(1)}$.

Constata-se que na convivência diária e prolongada, no ambiente laboral ocorrem a interação e a integração entre os profissionais, com identificação de afinidades e consequente formação de vínculos afetivos. Nesse conviver, acontece a partilha de sentimentos, de experiências e de conquistas, as quais fortalecem os laços afetivos e conduzem a uma relação mais íntima e próxima ${ }^{(7)}$. O diálogo e o contato humano são embasados na ética, no respeito e na condição dos seres como sujeitos de direitos, desejos e saberes ${ }^{(3)}$.

$\mathrm{Na}$ multiplicidade de relações identificadas no estudo, o cuidado "do nós" envolve uma diversidade de pessoas conectadas por meio de cuidado. Essas relações são estabelecidas junto aos profissionais de enfermagem e de saúde, articuladores e promotores de cuidado entre si. Assim, o cuidado é único no seu sentido e múltiplo no seu processar, pois articula múltiplas relações de cuidado.

Corrobora-se que, o cuidado "do nós" remete à compreensão dos fenômenos múltiplos e inesgotáveis da constante associação entre os seres e desses com o seu ambiente, cujas relações se modificam, alteram e fazem alterar as relações humanas existentes. Haja vista ser um tema emergente e que está em construção, o cuidado "do nós" denota constante movimento e impele continuidade, processo e investigações cada vez 
mais profundas acerca dos seus significados, como o entendimento de cuidado coletivo ${ }^{(7)}$.

Neste sentido, conforme os resultados, o cuidado "do nós" comporta o conceito de coletivo, frequentemente utilizado nas ciências humanas e sociais para designar uma dimensão da realidade que se opõe a uma dimensão individual, que separa objetos e saberes, indivíduos e sociedade. Entendido desta maneira, o coletivo é representado pelos profissionais na dimensão da interação humana individual ou grupal ${ }^{(9)}$.

A perspectiva de coletivo movimenta possibilidades de os profissionais de enfermagem e de saúde compartilharem, trocarem e conviverem entre si, nos encontros e desencontros cotidianos no ambiente hospitalar, considerando as subjetividades singulares dos envolvidos. Nessa perspectiva, a concepção de cuidado coletivo resulta de ações individuais voltadas para alcançar outras pessoas ou grupos $^{(10)}$. Por tratar-se de coletivo, nos encontros entre os profissionais, acontecem multiplicações e ressonâncias de ações, de experiências e de vivências que se inter-relacionam para o cuidado "do nós"(11).

O cuidado "do nós" experienciado pelos profissionais de enfermagem e de saúde, participantes do estudo em questão, designa responsabilidade coletiva de cada um em relação ao que é de todos. Destarte, a conduta de cada profissional, que comporta os múltiplos aspectos sociais, culturais, ambientais, educacionais, religiosos, entre outros, condiciona a conduta de outros profissionais, e reflete tanto o produto da coletividade como o cuidado com o ambiente, a natureza e o Planeta ${ }^{(7,12-13)}$.

Em sua multidimensionalidade e complexidade, o cuidado "do nós" no ambiente hospitalar acontece na interação entre os profissionais e desses com outros seres e com o seu ambiente, os quais estabelecem um relação de interdependência para o cuidado coletivo e multidimensional ${ }^{(11)}$. Logo, a interdependência entre os profissionais de enfermagem e de saúde beneficia tanto as relações interpessoais de cuidado no trabalho, quanto o cuidado prestado ao paciente ${ }^{(14)}$.

O cuidado "do nós", entendido como um cuidado coletivo, ao englobar outros seres de relação, representa um conjunto/equipe/grupo/ reunião de pessoas/de profissionais. Ocorre na interação entre os profissionais, no pensar coletivo e na responsabilização destes por atitudes, condutas e decisões que abrangem o cuidado de múltiplos seres, significando incluir o eu no coletivo como participante ativo dessa relação ${ }^{(12)}$.

Pensara complexidade das relações einterações para entender o significado de cuidado "do nós"। coletivo implica o exercício da consciência de si pelo profissional e do que está no seu entorno, bem como a percepção da interdependência das relações de si com o mundo, com o outro, com os outros. O cuidado "do nós"/do coletivo envolve a complexidade das relações humanas, que se movimenta na certeza e na incerteza, na lógica e na contradição, no racional e no irracional, que se organiza e desorganiza, se equilibra e desequilibra no movimento dinâmico do universo ${ }^{(4)}$.

Na linha deste raciocínio, é possível identificar que pacientes e seus familiares fazem parte das interações humanas de cuidado "do nós" dos profissionais de enfermagem e de saúde, cujos primeiros são o elo de ligação entre os demais. Os profissionais, em suas ações de cuidado, pensadas para os pacientes, promovem o processo de referência e contra- referência em saúde; asseguram a continuidade e a avaliação das intervenções propostas na alta hospitalar ${ }^{(15)}$. A atenção em saúde também permeia o momento pós-alta, com a adequada orientação e acompanhamento profissional da família para o seguimento dos cuidados no domicílio(16).

Confirma-se, portanto que, o processo interativo favorece o encontro e o estabelecimento de vínculo entre profissional, paciente e sua família( ${ }^{(3)}$. Nessas interações, identificamse atitudes altruístas e benevolentes dos profissionais pelo compromisso com o cuidado humano e pelos pacientes e família pela satisfação relacionada com a qualidade dos cuidados de enfermagem $^{(17)}$. As atitudes da enfermagem, no cuidado das famílias, são favoráveis quando entendem sua presença como importante ${ }^{(18)}$. Já as atitudes solidárias dos familiares com a equipe de enfermagem criam um clima favorável para que as relações de cuidado se estabeleçam ${ }^{(3)}$.

A espiritualidade também está presente nas ações de cuidado deste estudo. Os trabalhadores de enfermagem cultivam a sua espiritualidade no ambiente de trabalho ${ }^{(19)}$ como suporte no processo de recuperação do doente. A oração, em intenção à recuperação, demonstra a fé no cuidado do paciente e da família, um cuidado espiritual $^{(20)}$. 


\section{CONCLUSÕES}

O estudo permitiu compreender o cuidado "do nós" processado nas relações e interações estabelecidas por profissionais de enfermagem e de saúde como relacional e processual, manifestado por meio de ações e atitudes de cuidado entre os profissionais. Ocorre desde o modo de chegar e de abordar as pessoas, com demonstração de respeito, de interesse e de preocupação com o outro, aos modos de interação com o ambiente e os sujeitos envolvidos.

Evidenciou-se que o cuidado "do nós" está atrelado ao cuidado coletivo por integrar múltiplas relações; por envolver uma multiplicidade de sujeitos que se inter-relacionam no âmbito hospitalar e fora dele, cujo cuidado ultrapassa as relações profissionais, as relações com o paciente e sua família, pois envolve outras relações socialmente estabelecidas. As relações e interações de cuidado revelaram uma dinâmica não linear, de número ilimitado de associações, que processa e expressa o cuidado "do nós" de forma ampla e complexa.

Entende-se ser uma limitação do estudo, abordar um tema complexo e repleto de significados em apenas uma realidade, os quais podem e devem ser explorados em outros ambientes sociais e de saúde.

\section{REFERÊNCIAS}

1. Schaurich D, Crossetti MGO. O elemento dialógico no cuidado de enfermagem: um ensaio com base em Martin Buber. Esc. Anna Nery. [Internet] 2008;12(3) [acesso em 04 fev 2015]. Disponível: http://www.scielo. br/pdf/ean/v12n3/v12n3a22

2. Baggio MA, Callegaro GD, Erdmann AL. Compreendendo as dimensões de cuidado em uma unidade de emergência hospitalar. Rev. Bras. Enferm. [Internet] 2008;61(5) [acesso em 20jan 2015]. Disponível: http://dx.doi.org/10.1590/S0034-71672008000500004

3. Lanzoni GMM, Lessmann JC, Sousa FGM, Erdmann AL, Meirelles BHS. Interações no ambiente de cuidado: explorando publicações de Enfermagem. Rev. Bras. Enferm. [Internet] 2011;64(3) [acesso em 18 fev 2015]. Disponível: http://dx.doi.org/10.1590/S003471672011000300024

4. Morin E. Introdução ao pensamento complexo. $4^{\mathrm{a}}$ ed. Porto Alegre: Sulina; 2011.

5. Morin E. Os sete saberes necessários à educação do futuro. $2^{a}$ ed. São Paulo: Cortez; 2011.

6. Strauss A, Corbin J. Pesquisa qualitativa: técnicas e procedimentos para desenvolvimento da teoria fundamentada. $2^{a}$ ed. Porto Alegre: Artmed; 2008.

7. Baggio MA, Erdmann AL. Multiple relationships of nursing care: the emergence of care "of the us". Rev Latino-Am Enfermagem. [Internet] 2010;18(5) [acesso em 12 fev 2015]. Disponível: http://dx.doi.org/10.1590/ S0104-11692010000500009

8. Martins JJ, Backes DS, Cardoso RS, Erdmann AL, Albuquerque GL. Resignificando la humanización desde el cuidado en el curso de vivir humano. Rev. Enferm. UERJ. [Internet] 2008;16(2) [acesso em 28 jan 2015]. Disponível: http://www.facenf.uerj.br/v16n2/ v16n2a22.pdf

9. Escóssia L, Kastrup V. O conceito de coletivo como superação da dicotomia indivíduo sociedade. Psicol. estud. [Internet] 2005;10(2) [acesso em 16 mar 2015]. Disponível: http://dx.doi.org/10.1590/S141373722005000200017

10. Fortuna CM, Matumoto S, Pereira MJB, Mishima SM, Kawata LS, Camargo-Borges C. Nurses and the collective care practices within the family health strategy. Rev. Latino-Am. Enfermagem. [Internet] 2011;19(3) [acesso em 05 abr 2015]. Disponível: http:// dx.doi.org/10.1590/S0104-11692011000300018

11. Baggio MA, Callegaro GD, Erdmann AL. Significando o cuidado ecológico/planetário/coletivo/do ambiente à luz do pensamento complexo. Reme, Rev. Min. Enferm. [Internet] 2011;15(1) [acesso em 23 mar 2015]. Disponível: http://www.enf.ufmg.br/site_novo/ modules/mastop_publish/files/files_4e1dbbb6670cc. pdf

12. Baggio MA, Monticelli M, Erdmann AL. Cuidando de si, do outro e "do nós" na perspectiva da complexidade. Rev. Bras. Enferm. [Internet] 2009;62(4) [acesso em 17 abr 2015]. Disponível: http://dx.doi. org/10.1590/S0034-71672009000400023

13. Pereira MS, Souza ACS. Problemas ambientais, sustentabilidade e a pesquisa em enfermagem. Rev. Eletr. Enf. [Internet] 2013;15(2) [acesso em 14 fev 2015]. Disponível: http://dx.doi.org/10.5216/ree.v15i2.15161

14. Garcia AB, Dellaroza MSG, Haddad MCL, Pachemshy LR. Prazer no trabalho de técnicos de enfermagem do pronto-socorro de um hospital universitário público. Rev. Gaúcha Enferm. [Internet] 2012;33(2) [acesso em 18 abr 2015]. Disponível: http://dx.doi.org/10.1590/ S1983-14472012000200022

15. Barbosa PMK, Marcacine KO. Sistematização da Assistência de Enfermagem: uma contribuição para o processo de ensino-aprendizagem ao paciente e familiares. Rev Nursing. 2009;11(128):26-34.

16. Favero L, Mazza VA, Lacerda MR. Home care nurse's experiencing transpersonal care to a family 
of a neonate discharged from an intensive care unit: case study. Online Braz. J. Nurs. [Internet] 2010;9(1) [acesso em 24 fev 2015]. Disponível: http://dx.doi. org/10.5935/1676-4285.20102707

17. Yagil D, Luria G, Admi H, Moshe-Eilon Y, Linn S. Parents, spouses, and children of hospitalized patients: evaluation of nursing care. J. Adv. Nurs. [Internet] 2010;66(8) [acesso em 08 mar 2015]. Disponível: http:// dx.doi.org/10.1111/j.1365-2648.2010.05315.x

18. Fisher $\mathrm{C}$, Lindhorst $\mathrm{H}$, Matthews $\mathrm{T}$, Munroe DJ, Paulin D, Scott D. Nursing staff attitudes and behaviours regarding family presence in the hospital setting. J. Adv. Nurs. [Internet] 2008;64(6) [acesso em 16 fev 2015]. Disponível: http://dx.doi.org/10.1111/ j.1365-2648.2008.04828.x

19. Caldeira S, Gomes AC, Frederico M. De um novo paradigma na gestão dos enfermeiros-a espiritualidade no local de trabalho. Rev. Enf. Ref. [Internet] 2011;3(3) [acesso em 27 jan 2015]. Disponível: https://dx.doi. org/10.12707/RII1066

20. Campana HCR, Domingos ACP, Sanches PG, Correa DAM. A percepção dos mestrandos de enfermagem a respeito da religião como recurso terapêutico no processo de recuperação do ser humano doente e sua família. Cogitare enferm. [Internet] 2008;13(1) [acesso em 19 mar 2015]. Disponível: http://dx.doi.org/10.5380/ ce.v13i1.11950 